\title{
COMUNIDADE DE PRÁTICAS E REDES SOCIAIS: UM GRUPO DE DISCUSSÃO SOBRE LEITURA E PRODUÇÃO DE TEXTOS ACADÊMICOS NO FACEBOOK
}

\section{COMMUNITIES OF PRACTICE: A DISCUSSION GROUP ABOUT READING AND PRODUCING ACADEMIC TEXTS ON FACEBOOK}

\author{
Heitor Gonçalves Lima ${ }^{1}$ \\ Júlio Araújo ${ }^{2}$
}

\begin{abstract}
RESUMO
Comunidade de prática é um conceito trabalhado por Swales (1998) que caracteriza certo grupo que produz conhecimento em conjunto, o qual se conecta à noção deaffordances(OLIVEIRA, 2012) que, com base em Paiva (2009) e Azevedo e Novais (2010), diz respeito às propriedades que determinado ambiente proporciona aos seus usuários. Considerando como os Novos Estudos do Letramento (BEVILAQUA, 2013) podem influenciar nesse processo, nossa pesquisa visa observar e avaliar à luz das teorias citadas o funcionamento de um grupo fechado de alunos na rede social Facebook chamado Leitura e Produção de Textos Acadêmicos, homônimo da disciplina obrigatória a qual os participantes, graduandos do curso de Letras da Universidade Federal do Ceará, devem compor. O grupo funciona como uma ferramenta de interação a respeito dos conteúdos apresentados em sala de aula. Por meio da observação das interações entre o período de março a junho, que compreende o semestre letivo 2014.1, percebemos que as características do grupo em questão são suficientes para que ele seja denominado comunidade de prática.
\end{abstract}

Palavras-chave: Comunidade de Prática. Affordance. Novos Estudos do Letramento.

\begin{abstract}
Communities of practice is a concept wrought by Swales (1998) that characterizes some group that produce knowledge together, which establishes a connection with the concept of affordances (OLIVEIRA, 2012) that, according to Paiva (2009) and Azevedo and Novais (2010), regards the properties that some environment provides to their users. Considering how the New Studies of Literacy (BEVILAQUA, 2013) can exert influence in this process, our research aims to observe and evaluate according to the cited theories the operation of a closed student group on the network Facebook called Reading and Producing Academic Texts, namesake of the required discipline that the participants, all graduating students in Letras course, must compose. The group works as a tool of interaction about the contents presented in the classes. Through the observation of the interactions among the period of March till June, which comprises the academic semester 2014.1, we realizes that the
\end{abstract}

\footnotetext{
${ }^{1}$ Curso de Letras - Português e Inglês da Universidade Federal do Ceará - UFC.Hiperged. E-mail: heitorlima17@hotmail.com

${ }^{2}$ Docente no Programa de Pós-Graduação em Linguística, do Departamento de Letras Vernáculas da Universidade Federal do Ceará - UFC. Hiperged. E-mail: araujo@letras.ufc.br
} 
characteristics of the concerned group are sufficient to make it be named community of practice.

Key-words: Communities of Practice. Affordance. New Studies of Literacy.

\section{Introdução}

O ser humano sempre passa por mudanças sociais na medida em que o avanço no conhecimento acontece. $\mathrm{O}$ advento da Internet no domínio tecnológico do conhecimento tem sido, desde o começo, um instrumento de transformações intensas e tem tomado todos os âmbitos da vida em sociedade, não fazendo mais muito sentido, no contexto atual, separarmos o virtual do real. Essas transformações trazem impacto sobre os relacionamentos pessoais e profissionais, os quais impulsionam o uso da rede como uma extensão dos ambientes off-line. Essa tem sido uma forma de manter contato para atender a qualquer propósito que surja em função da impossibilidade de encontros presenciais, sendo esse um forte motivo para que a barreira que separa o virtual do real perca relevância hoje em dia.

Dentro das inúmeras possibilidades que a Internet disponibiliza, as redes sociais surgiram como uma ferramenta tímida, de poucos usuários e de acesso restrito. No Brasil, começou com o extinto Orkut e depois, paulatinamente, as pessoas foram conhecendo e aderindo a outras redes sociais digitais, como o Facebook e o Twitter. O acesso foi crescendo na medida em que as barreiras para adquirir um computador ou dispositivo móvel com um acesso cada vez mais facilitado à Internet foram e vão sendo derrubadas. Sendo assim, o número de acessos e usuários da rede mundial de computadores permanece em constante crescimento. Chegamos a um ponto em que é difícil encontrarmos alguém que tenha acesso frequente à Internet que não tenha um perfil em uma ou outra rede social.

Dentro desse grupo tão heterogêneo de redes sociais que se colocam a serviço dos usuários como uma gama de opções entre as quais o usuário pode escolher aquela com a que mais se identificar, existem as que se destacam. Podemos lembrar que não faz muito tempo que a rede social mais popular no Brasil era o Orkut, sítio que passava por 
constantes mudanças em seu design e ferramentas, mudanças que o faziam se aproximar cada vez mais do concorrente que acabou assumindo seu lugar: o Facebook ${ }^{3}$.

A rede social que surgiu dentro do contexto universitário dos Estados Unidos foi lentamente conquistando os usuários do Orkut, que migraram quase que totalmente para o novo sítio. Essa preferência foi tão radical que o Google, responsável pela manutenção do Orkut, optou por dar fim, em 2014, à rede social, que teve seus anos de evidência claramente encerrados. Mesmo aqueles poucos usuários que insistiam em se identificar mais com a proposta de interação promovida pelo Orkut tiveram, então, de deixar o sítio para trás.

Não foi somente no Brasil que o Facebook assumiu a posição de rede social mais popular. A nível mundial, a rede social, que já teve sua história transformada em filme, acumula números recordes e domina a Internet estabelecendo conexões com outras redes sociais de destaque e comprando aplicativos de smartphones cujo funcionamento acrescenta à sua proposta. Criado um perfil no Facebook, o usuário tem, dentre outras possibilidades, a oportunidade de criar grupos ou fazer parte deles, os quais podem se constituir num caráter público ou fechado, que são feitos para que pessoas com um interesse em comum promovam tópicos e discussões direcionadas.

Esses grupos podem se desenvolver em diversas modalidades. Podem ser encontrados grupos de caráter lúdico, feitos para que se compartilhem conteúdos de lazer e passatempo. Há os grupos que juntam pessoas que têm em comum a admiração por determinado profissional, artista ou personalidade. Há aqueles que reúnem pessoas que frequentam um mesmo ambiente e cujos problemas são compartilhados para que se ache uma solução baseada na experiência dos membros. Daremos, contudo, mais evidência a uma das várias modalidades que esses grupos comportam: a pedagógica. Observando os grupos que se encaixam nessa modalidade, notamos que eles possuem ferramentas que ampliam as possibilidades de responder às demandas de um determinado um grupo de pessoas com o interesse de promover discussões a respeito de determinada área do conhecimento.

${ }^{3} \mathrm{O}$ IBGE atesta que metade da população brasileira acessa à internet por dispositivos móveis ou por computadores.http://www.ibge.gov.br/home/estatistica/populacao/acessoainternet2013/default.shtm 
A criação de um grupo no Facebook é bem simples. Basta que o proponente tenha um perfil nessa rede social para ter a possibilidade de cria-lo. Uma vez pronto, o autor pode optar por definir o grupo como fechado ou aberto, o que determinará o acesso de outras pessoas, que, dependendo da escolha, se dá de maneira livre ou deliberadamente selecionada. A qualquer momento a partir da criação, qualquer integrante do grupo pode criar tópicos nos quais é possível fazer comentários, o que se assemelha a um fórum. No próprio site e na web existem alguns detalhes que são disponibilizados para o administrador para criar uma identidade no grupo e alguns privilégios administrativos.

É nesse contexto que encontramos o grupo fechado Leitura e Produção de Textos Acadêmicos (doravante LPTA). Ele faz parte das atividades da disciplina homônima de caráter obrigatório da grade do curso de Letras da Universidade Federal do Ceará e foi criado por seu docente para que fosse uma ferramenta que ajudasse a dar conta de todo o cronograma demasiado intenso que a disciplina tem, além de facilitar o contato entre alunos, professores bolsistas e estagiários de docência ${ }^{4}$ (ARAÚJO, SILVA, MARQUES, 2014). Podemos ver que, a partir de todas as ferramentas que o grupo possui propiciamentos $^{5}$ que possibilitam a interação - LPTA funciona como uma comunidade de prática cujos membros promovem discussões em tópicos direcionados a assuntos concernentes ao conteúdo visto em sala, o que gera uma aproximação e ampliação dos letramentos acadêmicos de seus participantes.

Percebidas as características recorrentes em grupos nomeados comunidades de prática, no presente artigo, visamos relacionar cada aspecto de LPTA que contribui para a sua caracterização pedagógica a fim de defini-lo como uma comunidade de prática cujos membros em atividade se utilizam de seus propiciamentos para se aproximam dos letramentos acadêmicos, atingindo, assim, o propósito da disciplina.

Optamos por organizar o presente artigo, a partir daqui, nas seções de fundamentação teórica, metodologia, análise dos dados e conclusão. Na primeira, trabalhamos os conceitos necessários para o entendimento e funcionamento de uma comunidade de prática e os aspectos que ela envolve. Logo em seguida, discorremos sobre

\footnotetext{
${ }^{4}$ Notadamente, doutorandos e mestrandos do Programa de Pós-Graduação em Linguística e, algumas vezes, do Programa de Pós-Graduação em Educação Brasileira, ambos os programas da UFC.

${ }^{5}$ Tradução para a categoria affordances proposta por Paiva (2010) e adotada neste artigo.
} 
a composição do grupo e o processo da geração de dados, o montante de material coletado, sua categorização e critérios para a seleção da análise. Na subsequência, aplicaremos os conceitos e teorias expostos na fundamentação teórica em exemplos selecionados do material empírico a fim de demonstrar sua concretização no funcionamento do grupo. Finalmente, faremos uma retomada dos principais aspectos do trabalho a fim concluirmos o raciocínio e reafirmar os resultados.

Para entender como funciona uma comunidade de prática e perceber o desenvolvimento de LPTA, assim como a possibilidade de sua definição como comunidade de prática, passemos para um breve estudo sobre o conceito de comunidade de prática e aquilo que ele envolve.

\section{Fundamentação Teórica}

Swales (1998) fornece um quadro geral de como a noção de comunidades de prática surgiu há alguns anos dentro das universidades americanas quando se percebeu um déficit de conhecimento sobre informática e um programa de assistência foi criado para suprir a carência dos alunos. Como demonstra o autor, grupos semelhantes começaram a surgir posteriormente, os quais passavam por constantes modificações cada vez que se mostrava necessário. Dada a multiplicação desses grupos, a possibilidade de que participamos de várias comunidades de prática - mesmo sem termos a consciência de tal fato - nos motiva a compreender o funcionamento de tais grupos para identificarmos e tirarmos melhor proveito deles. A identificação de uma comunidade de prática, de acordo com Oliveira (2012), começa pelo nome. Em nosso caso, o grupo é nomeado pela expressão Leitura e Produção de Textos Acadêmicos. A partir dessa percepção, passamos para aspectos mais internos, como o desempenho dos participantes. Oliveira (2012) destaca que a participação dos integrantes de uma comunidade de prática pode se dar de forma central ou ocasional, o que depende da configuração particular de cada uma.

O funcionamento característico das comunidades de prática demonstra as várias possibilidades de interação e aprendizado disponíveis para o participante. Swales (1998) não contava com uma nomenclatura para trabalhar esse fenômeno, a qual veio algum 
tempo depois em estudos que o classificaram como propiciamentos, termo que, de acordo com Paiva (2009),vem da área da ecologia e faz referência às possibilidades de interação dos seres vivos em relação ao ambiente, o qual proporciona o uso de seus recursos para que se alcance determinado objetivo dentro dele. O conceito de propiciamento logo foi incorporado pelos estudos linguísticos, pois a linguagem humana é vista como o "habitat natural dos processos de interação" (AZEVEDO, NOVAIS, 2010, p.2).

O uso do referido conceito nesse contexto é bastante conveniente, uma vez que podemos notar que ele se aplica de modo integral ao ambiente da comunidade de prática, pois cada participante conta, dentro da comunidade, com determinadas possibilidades de interação que os conduz à produção e ao compartilhamento de conhecimento, e isso pode variar de acordo com o grupo, especialmente no que diz respeito à modalidade de encontro utilizada. Oliveira (2012, p. 175) confirma esse raciocínio quando define muito bem que “comunidades de prática são grupos de pessoas que dividem mesmos problemas ou paixão por um tópico". Essa parece ser a principal condição para a existência de uma comunidade de prática, ficando a qualidade do encontro em segundo plano.

No mesmo raciocínio, Oliveira (2012, p. 175) continua dizendo que comunidades de prática "estão em todos os lugares e nós pertencemos a várias - e muitas vezes nem percebemos essa participação.” Essa informação curiosa nos motiva a desenvolver essa pesquisa, uma vez que a consciência nos faz aproveitar melhor aquilo que sabemos. Participar, portanto, de uma comunidade de prática ciente de como seu funcionamento ocorre, naturalmente acabará por produzir melhores resultados, o que aqui é entendido como produção de mais conhecimento.

Sabemos que procurar solução para um problema sozinho demanda mais esforço, mais trabalho e, muitas vezes, menos resultado. Fazer isso em grupo é uma boa forma de alcançar produtividade e ser parte de uma comunidade de prática se apresenta como um bom caminho para isso. Segundo Oliveira (2012, p. 176),

\footnotetext{
Apesar de essas comunidades serem mais informais, elas focam o conhecimento e a aprendizagem. Sua definição pode ser dada através de três palavras: domínio, comunidade e prática. O domínio é o assunto, tópico que interessa a um grupo de pessoas, que seria então uma comunidade. Juntos eles desenvolvem e aprendem mais sobre o domínio que possuem em comum, constituindo assim uma prática. (OLIVEIRA, 2012, p.176)
} 
Entendemos assim que os elementos trazidos até agora são imprescindíveis para a composição e reconhecimento de uma comunidade de prática. Não podemos deixar de levar em consideração, contudo, o aspecto do tipo de encontro através do qual a comunidade funciona. Em tempos de redes sociais, quando a presença física tem sido contornada sempre que possível por contatos via Internet, é esperado que organizações como comunidades de prática fossem também atingidas por isso. Dentro desse contexto, Wenger, Medermott e Snyder (2002) classificam comunidades de prática que não são dependentes de encontros presenciais como principal modalidade para acontecer de comunidades distribuídas.

Dentro desse ambiente virtual percebemos de maneira bem peculiar a presença dos propiciamentos. Van Lier (2004)e Turolo-Silva (2015) mostram propiciamentos como aquilo que está à disposição para uso pessoal. Percebemos várias opções utilizáveis dentro de um grupo que utiliza a plataforma do Facebook para existir de modo a promover e facilitar a interação. Rapidamente podemos elencar aqui a possibilidade de montar uma publicação, que entendemos como sendo a criação de um tópico. Dentro da publicação, temos a opção de comentar, o que entendemos por postagem. Entre esses fenômenos, podemos "curtir", opção que tem ganhado cada vez mais significados dentro do contexto da rede social(RECUERO, 2014), editar a publicação ou postagem e até mesmo marcar outra pessoa do grupo no tópico, mecanismo que notifica especificamente a pessoa marcada e faz como que um chamamento à discussão.

É natural que o funcionamento do grupo comece com certo peso de dependência sobre os professores, estagiários de docência e bolsistas no que diz respeito à criação de publicações e condução de discussões, uma vez que quem tem mais experiência acaba ganhando mais espaço e mais crédito naquilo que diz, fenômeno suportado pelos alunos, ainda que de forma inconsciente. Em outras palavras, os professores e bolsistas são a parcela do grupo que mais publica e posta em LPTA, pelo menos no começo do semestre. Normalmente, com o passar do tempo, os alunos vão adquirindo mais conhecimento e conteúdo suficiente que faz com que eles passem a ter condições de promover discussões e criar tópicos dentro do grupo. Isso tudo funciona como uma mudança de zona dentro do grupo, como se houvesse uma primeira zona em que o integrante somente observa o que 
está acontecendo enquanto aprende para, depois, passar para uma zona em que pode ter participação ativa:

Podemos perceber ainda que essas ferramentas propiciam um ambiente de aprendizagem situada. (LAVE; WENGER, 1991), visto que para pertencer a uma comunidade, você não precisa necessariamente ser um participante ativo; o fato de estar inserido e fazendo parte das discussões abordadas ali, por exemplo, faz com que a pessoa possa, no futuro, participar de forma ativa. Os autores afirmam que a periferalidade é uma posição de empoderamento, ou seja, é uma posição que oferece possibilidades de aprendizagem para que no futuro haja a participação de forma completa. (OLIVEIRA, 2012, p.176)

Essa mudança de zona nos leva a um aspecto fundamental do grupo LPTA, que são os letramentos acadêmicos (LEA; STREET, 2006; DIEB, 2015). Sair da zona da periferalidade é adquirir letramento acadêmico, uma vez que se aprende o que está sendo ensinado, fenômeno que permite a discussão do conteúdo, esclarecimento de dúvidas e avanço no conhecimento. Lea e Street (2006) nos mostram que a abordagem dos letramentos acadêmicos está fundamentada em três raciocínios. O primeiro é a crença de que os alunos podem transferir seus conhecimentos sobre a habilidade da escrita de um contexto para o outro. No caso de LPTA, os alunos estão adaptando seus letramentos escolares pelos letramentos necessários dentro do ambiente acadêmico, processo que abre brecha para muitas dúvidas. O segundo raciocínio se baseia na relativa estabilidade dos gêneros, a qual o aluno pode se familiarizar e reproduzir corretamente sob a devida orientação. O terceiro raciocínio avança em relação aos anteriores uma vez que, adquirida a habilidade necessária para a reprodução dos gêneros, é preciso que se leve em consideração seus aspectos sociais, os lugares onde os gêneros podem acontecer e como eles funcionam dentro de cada um.

A comunidade de prática LPTA é um lugar virtual, situado como um grupo no Facebook, no qual podemos perceber os alunos passando por esses três estágios. Na medida em que os conteúdos vão sendo expostos em sala de aula presencial e que é requerida a produção de textos acadêmicos mais elaborados, o que possibilita a conferência da habilidade, cada integrante se aproxima do objetivo da disciplina, que se caracteriza por oportunizar possibilidades da ampliação dos letramentos dos estudantes que, paulatinamente, passam a ler e a produzir cada vez mais textos acadêmicos. 
Segundo Street (idem, p. 78), o modo como as pessoas se relacionam com a leitura e a escrita está 'enraizado' na representação dessas pessoas sobre o conhecimento. Por essa razão, o letramento não pode, como pressupõe o modelo autônomo, ser 'dado' aos sujeitos; ele será, conforme demonstram pesquisas etnográficas mais recentes (STREET, 2012), reformulado, reapropriado diferentemente de acordo com o contexto em que estiver inserido e de acordo com a identidade dos sujeitos membros de uma comunidade. (BEVILAQUA, 2013, p.104)

Finalmente, reconhecemos a importância de uma comunidade de prática dada a sua configuração virtual, que se dá fundamentalmente diferente da configuração de uma sala de aula presencial, onde outras atividades são possíveis conforme os objetivos e os participantes do evento. Paiva (2009) reforça esse raciocínio quando usa o exemplo de um projeto de estudo de língua estrangeira para esclarecer que, muitas vezes, a sala de aula não oferece propiciamentos suficientes para o aprendizado efetivo de uma segunda língua. É preciso se expor a situações e lidar com contextos diferentes para realmente colocar em prática aquilo que é visto em teoria, e a sala de aula simplesmente não alcança muitos deles. É preciso, portanto, buscar em ambientes externos à sala de aula propiciamentos que possibilitem o avanço necessário no conhecimento do conteúdo abordado, para que o aprendizado se efetive verdadeiramente. Assim como o projeto trazido por Paiva (2009) sofreu a constatação dessa necessidade, o grupo LPTA surgiu para procurar suprir esses propiciamentos difíceis de alcançar durante as aulas presenciais na universidade.

A composição do grupo, a geração de dados e o modo de análise que utilizamos para responder aos nossos objetivos são o próximo passo deste estudo.

\section{Metodologia}

Nossa pesquisa possui um caráter qualitativo porque, à luz dessa opção metodológica, podemos escolher três postagens do grupo LPTA para ilustrar a nossa argumentação e, então, atingir o nosso objetivo, que é descrever o referido grupo como uma genuína comunidade de prática. A geração de dados foi feita por meio do Print Screen, recurso que registra instantaneamente a imagem que está sendo exibida na tela do 
computador. Atentos ao princípio ético da pesquisa em ciências humanas, tivemos o cuidado de preservar a identidade de nossos colaboradores, manchando seus nomes e fotos dos dados registrados, focando apenas nos conteúdos das publicações postadas no grupo de discussão.

O grupo LPTA é formado pelos alunos que estão matriculados na disciplina de Leitura e Produção de Textos Acadêmicos no semestre corrente. Além deles, estão o professor docente da disciplina, criador do grupo e principal administrador; os estagiários de docência, normalmente orientandos de mestrado ou doutorado do professor docente, ao quais, além de comporem o grupo, também dão aulas no curso presencial; os bolsistas vinculados ao professor por meio do Programa de Iniciação à Docência (PID) da PróReitoria de Graduação da UFC os quais, na condição de monitores, assumem a função de co-orientar e acompanhar os estudantes matriculados na referida disciplina.

A parcela formada pelos professores, estagiários e bolsistas normalmente cria tópicos e guia os alunos na forma de se portar dentro do grupo, orientando a respeito do conteúdo que pode ser compartilhado e alertando sobre o que se espera que eles façam no grupo para que o objetivo seja atingido. Os alunos, por sua vez, vão interagindo e percebendo cada vez mais como o grupo pode ser produtivo, especialmente para assistências que seriam difíceis de conciliar fora do ambiente virtual.

As três postagens que selecionamos para análise foram escolhidas dentro de um montante de 227 publicações acumuladas entre os períodos 2014.1 e início de 2014.2. Após o processo de elaboração do banco de dados, procedemos a um exame inicial por meio do qual chegamos a duas categorias analíticas que nortearam o exercício de análise.

A primeira categoria que encontramos diz respeito a discussões de aspectos ligados à produção textual, assim como dúvidas a respeito dos gêneros acadêmicos abordados durante o transcorrer da disciplina. Dessas, temos 10 postagens do primeiro semestre e 5 postagens do segundo, as quais classificamos como aproximação dos letramentos acadêmicos. A segunda categoria diz respeito ao compartilhamento de material online, que abrange links de redirecionamento, downloads ou indicação de eventos de interesse comum, assim como avisos, lembretes e notificações. Dessas, temos 189 no primeiro 
semestre do ano letivo e 23 no segundo semestre do mesmo ano, as quais classificamos como percepção de propiciamentos.

Diante desse universo, que totaliza 227 publicações, procedemos à escolha de três postagens, pois as identificamos como apropriadas para atender aos nossos objetivos. Assim, o critério que iluminou a escolha dessas três postagens foi, primeiramente, a relevância quanto à intensidade de interação e, em segundo plano, o assunto da publicação, cuja importância consideramos de acordo com as atividades do curso. Falando de maneira mais específica, a escolha do primeiro exemplo teve por base a quantidade de interações, pois nela encontramos o maior número de comentários, curtidas, visualizações e marcações. O segundo motivo diz respeito à importância do assunto, uma vez que a publicação do primeiro exemplo, feita pelo docente, se trata de uma discussão acerca do tema e da delimitação do tema do projeto de pesquisa que os alunos têm que produzir como principal atividade escrita do semestre.

O segundo exemplo, uma publicação de um aluno feita para tirar uma dúvida a respeito do gênero resenha, apesar de não ter tido tanta interação - não obstante significativas - apresenta um assunto de grande importância, pois o gênero em questão é o que mais recebe atenção na disciplina logo após do projeto de pesquisa (ARAÚJO, BARROS, SILVA, 2015). Sendo a única publicação feita por um aluno para, especificamente, pedir ajuda no meio da produção de uma resenha, a consideramos como relevante para estar presente no artigo.

O terceiro exemplo, apesar de também não ter tanta interação, apresenta-se como única publicação em todo o grupo a respeito da impossibilidade de interagir em função da perda de um dispositivo móvel com acesso à Internet. Consideramos relevante para que trabalhemos o aspecto de independência do grupo em relação ao que acontece em sala de aula durante a ministração da disciplina.

Dadas as informações a respeito dos nossos exemplos, passemos para o estudo deles em consonância com os estudos que servirão de base para nossa argumentação. 


\section{Análise dos dados}

No registro abaixo, podemos perceber o andamento da postagem em que o professor pede para que seus alunos publiquem o grupo os seus temas e suas respectivas delimitações. É possível inferir que tudo o que for postado ali estará sujeito à discussão. Dificilmente, portanto, algum representante de grupo disponibilizará seus dados de modo que ajustes não sejam sugeridos pelo professore pela sua equipe de responsáveis pela disciplina e pela administração do grupo virtual.

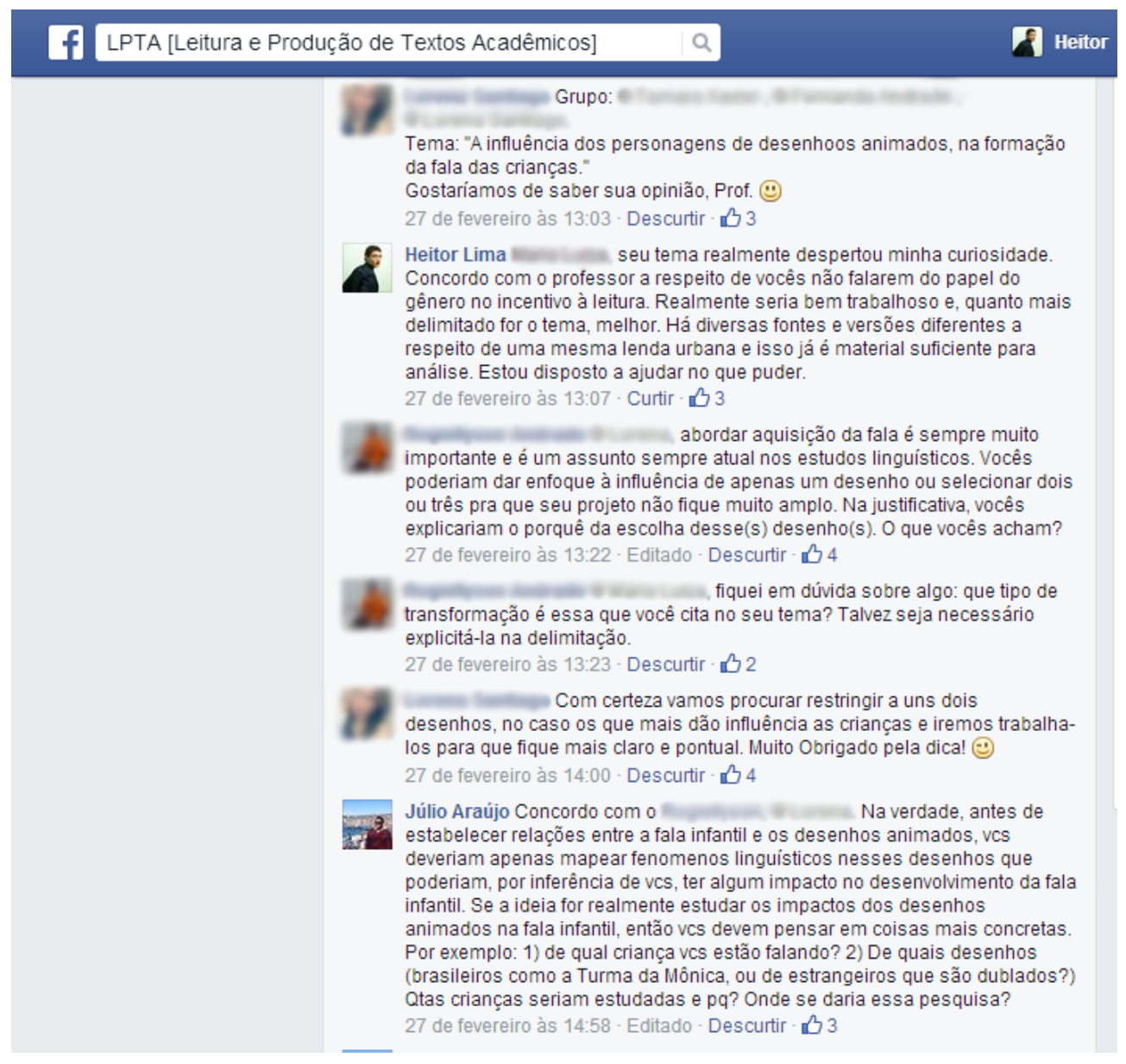

Figura 1- Aproximação dos Letramentos Acadêmicos I

A figura acima mostra que a perspectiva pedagógica adotada pelo professor e o engajamento de todos em sua proposta de discussão aproxima o grupo de LPTA à definição de Wenger; McDermott; Snyder (2002) para quem as comunidades de prática são ambientes de compartilhamento de problemas acerca de um mesmo tópico. Como bem 
ilustra a figura 1, acima, os estudantes estão todos interessados em aprender juntos sobre o processo de delimitação do tema.

Também percebemos, na mesma figura 1, indícios de letramentos acadêmicos (LEA; STREET, 2006), pois, nele, trata-se de aspectos intrínsecos à atividade de produção do gênero projeto de pesquisa. Notamos aí os três componentes que configuram as comunidades de prática e fundamentam sua constituição que, de acordo com Oliveira (2012), são o domínio, que se mostra aqui como o assunto - discussão a respeito do tema e da delimitação do tema do projeto de pesquisa - que se dá no meio de um grupo de pessoas que tem um objetivo em comum, fato que revela a comunidade. A manutenção da discussão, assim como os avanços acrescentados pelos mais experientes, constrói a prática.

Podemos notar ainda a abundância de ferramentas - aqui vistas como propiciamentos- que os usuários têm à disposição para interagir dentro da postagem. Logo no início da interação, temos a publicação de uma aluna, matriculada na disciplina, que expõe o seu tema e delimitação, conforme foi orientado que se fizesse. Além disso, ela informa quem são os outros integrantes do grupo por meio de marcações, recurso que a plataforma do Facebook disponibiliza, pela qual é possível notificar especificamente outro usuário da rede social registrado por aquele nome de que algo que o interessa está acontecendo. Esse, além de ser um chamado para a interação aos outros integrantes, é uma tentativa de fazer com que sua participação se dê da forma mais rápida possível, uma vez que a notificação é instantânea.

Notamos também que, ao fim de seu texto, a aluna registra um emoticon. Dentre todas as interpretações que esse fenômeno pode conter, tendemos a acreditar que o uso desse recurso foi uma forma de se proteger das possíveis críticas dos membros mais experientes. A aluna sabe que, uma vez expostos seus temas e delimitações, sua ideia passará por uma análise criteriosa pelos demais membros da comunidade de prática. Ao colocar o emoticon, ela o usa como uma estratégia de proteção de face, dando um caráter menos comprometedor ao seu texto, pedindo para que não sejam tão rígidos com ela. Se conferirmos a data e horário de interação, perceberemos que um dos monitores da disciplina dá um retorno para a aluna em apenas quatro minutos, depois de ter curtido a publicação anterior. Nisso, temos mais dois recursos presentes no grupo: a possibilidade de interação rápida e um indício de relevância da mensagem. Qualquer acontecimento no 
grupo gera notificações no perfil dos participantes, o que inclui os bolsistas, os quais, por sua vez, devem ver o que está sendo tratado no grupo para perceberem a necessidade de interação. Além disso, cremos que a opção curtir confere relevância ao texto, uma vez que essa é uma opção que dificilmente será ativada se o usuário não tiver lido a postagem em questão.

Finalmente, vemos o caráter de debate que esse tópico pode assumir, o qual mostra aqui dimensões bastante diferentes por ser um ambiente virtual. Em um ambiente presencial, como o de uma sala de aula convencional, onde se dá uma discussão dessa natureza, normalmente há interrupções que são substancialmente danosas, uma vez que essas interrupções podem levar a perca da linha de raciocínio ou mesmo a desestimular a quem for interrompido. Essa possibilidade simplesmente não existe em um grupo virtual como LPTA, pois percebemos que cada participante tem seu turno de fala bem estabelecido e não pode ser interrompido de maneira alguma, uma vez que seu texto só é publicado no grupo quando está completo. Isso promove uma maior riqueza teórica durante a discussão, pois não há possibilidade de alguém esquecer o que iria dizer, pelo menos não devido a uma interrupção dessa natureza.

Além disso, existe a possibilidade da edição de texto, o que ajuda o integrante do grupo em seu turno de fala a construir um texto coerente e satisfatório dentro de cada situação. O recurso de edição de texto na ferramenta de grupos do Facebook é um dispositivo relevante, pois permite ao participante consertar aquilo que foi escrito de maneira a deixar ainda mais clara a sua participação, algo que não tende a funcionar tão bem em uma sala de aula presencial. No decorrer de cada um dos turnos de fala percebemos que os alunos acompanham o raciocínio, aderem àquilo que acreditam ser o melhor para a sua situação e, assim, avançam nos conhecimentos necessários para o desempenho de suas atividades. Em outras palavras, a participação recorrente e atenciosa em LPTA possibilita aos alunos se aproximarem cada vez mais dos letramentos acadêmicos, fato que nosso próximo exemplo constata muito bem.

Na figura 2 podemos contemplar a criação de tópico por um aluno. O primeiro aspecto a ser observado nessa situação é que não são somente professores ou bolsistas que têm direito e recursos para promover discussões na construção dos tópicos. Van Lier (2004), fala sobre como os propiciamentos podem ser recursos disponíveis para todos os 
participantes de um de grupo. É interessante notar que o tópico marca uma transição percebida na participação dos alunos, a qual vai aumentando gradativamente. Lave; Wenger (1991) chamam esse lugar de observação de periferalidade, conceito entendido como estágio de aprendizado ocupado pelo participante que, mais tarde, terá condições de ser mais ativo no grupo. Ou seja, os participantes de uma comunidade de prática não precisam estar nivelados. Vemos nisso uma característica que promove o crescimento em grupo, uma vez que observar para, depois, interagir é absolutamente natural. Para ilustrar isso, vejamos, abaixo, a figura 2.

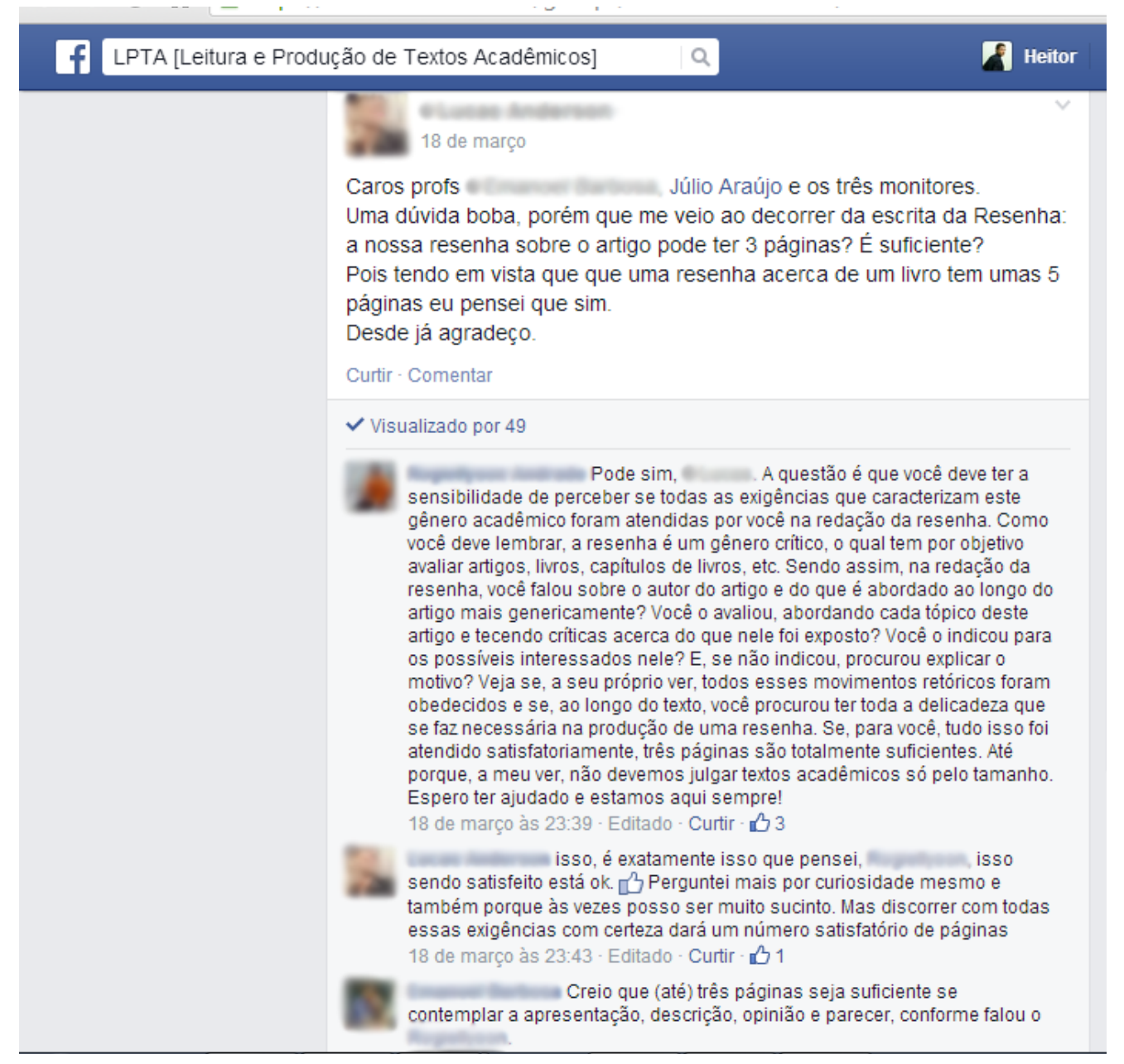

\section{Figura 2- Aproximação dos Letramentos Acadêmicos II}

Tomando a figura 2 como exemplo, podemos perceber que a dúvida do aluno já acusa certo conhecimento de sua parte, pois, como ele próprio diz, a dúvida veio no decorrer da escrita da resenha, o que sugere que ele tem conhecimento sobre os movimentos retóricos desse gênero, restando somente a dúvida sobre a extensão mais 
adequada para o texto, o que foi muito bem esclarecido pela primeira postagem seguinte, feita por um dos bolsistas. Primeiramente, foi apresentado em sala de aula o gênero resenha acadêmica, o qual consiste nos seus movimentos retóricos e veiculação. A partir do que foi exposto e proposto pelo professor e apreendido pelo aluno, este, aplicando o conhecimento adquirido no desempenho da atividade, preocupou-se em relação à extensão do texto. Entendemos, portanto, que, do momento em que a teoria foi exposta até o estudo individual do aluno, ele estava na zona da periferalidade. A sua criação do tópico marca a mudança de zona, pois ele deixou de observar para promover uma discussão motivada por dúvida, a qual, inclusive, tem potencial para encorajar os outros membros do grupo a participarem do tópico, assim como a criá-los quando a necessidade surgir.

A saída do aluno da zona da periferalidade nos mostra a aproximação que o aluno está tendo dos letramentos acadêmicos nesse processo. É importante levar em consideração que, além do que é trabalhado em sala de aula em relação aos gêneros estudados, existe à disposição dos alunos uma bibliografia reunida pelo professor, a qual tem, além de material didático que traz explanações sobre os gêneros, exemplos de textos como resenhas e projetos de pesquisas para que se perceba concretamente os gêneros ensinados em sala de aula, mostrando a aplicação das teorias. Ademais, durante o semestre, o professor promove vários sorteios de revistas acadêmicas e livros, o que promove uma inserção dos estudantes cada vez mais intensa no mundo dessa modalidade de escrita. Percebe-se, portanto, que são disponibilizados para os alunos fontes e recursos suficientes para a familiarização das práticas de letramentos acadêmicos.

Aprofundando o olhar sobre os propiciamentos presentes na figura 2, acima, podemos perceber, logo abaixo do texto do aluno, o indício de contagem de visualizações que a ferramenta disponibiliza. A postagem, até o momento de nosso registro, havia sido visualizada por 49 pessoas, as quais, curiosamente, não curtiram a criação do tópico. Há registro de curtidas, contudo, na resposta do monitor, o que nos leva a acreditar que foi conferida mais relevância à resposta do que à pergunta. Possivelmente, os três que curtiram tiveram o mesmo problema e tiraram proveito do exposto. É interessante notar também que tanto a resposta do bolsista quanto a réplica do aluno foram editadas. Isso quer dizer que, no momento em que a postagem foi feita, o escritor do texto percebeu algum erro ou imprecisão, que pode ser de natureza diversa, como problemas de digitação até problemas 
de ordem mais textual e, em função dessa percepção, pode proceder à edição de seus textos por meio dessa ferramenta de ajustes. Essa possibilidade é muito conveniente para que se refaça o que foi dito, evitando possíveis mal-entendidos e esclarecendo ideias mal trabalhadas, propriedades que ficam mais difíceis de serem realizadas presencialmente na sala de aula.

Ainda sobre os propiciamentos, temos nos exemplos anteriores demonstrações de como os recursos disponibilizados na plataforma do Facebook são eficientes no auxílio do suprimento das necessidades de seus usuários. Azevedo; Novais (2010, p.2) acentuam que "essas mídias trazem consigo ferramentas que ampliam a capacidade de interação". Percebemos que o Facebook é um espaço totalmente propício para o desenvolvimento de um grupo que venha ao encontro da proposta de Letramento Acadêmico lançada pela disciplina LPTA, pois, de acordo com Street (2014), o foco dos Novos Estudos do Letramento está em compreender práticas sociais de diferentes contextos, cuja realização se dá pela escrita, privilegiando o estudo ao invés do ensino. $\mathrm{O}$ ambiente virtual e os dispositivos pelos quais o acessamos ganham grande importância nesse contexto, conforme vemos na imagem abaixo.

LPTA foi criado por uma demanda percebida durante as primeiras turmas formadas na graduação de Letras da UFC: um semestre é pouco para dar conta de tudo que precisa ser feito na disciplina homônima. Como a alternativa de se ter mais tempo é de dificuldade extrema tanto pela grade rígida no programa de curso da universidade quando pela disponibilidade de agenda dos envolvidos, utilizar-se de uma plataforma onde a maioria pode se conectar a qualquer hora e em qualquer lugar aparece como uma ideia extremamente conveniente.

Wenger; McDermott; Snyder(2002)mostram que esse tipo de comunidade de prática também recebe o nome de comunidades distribuídas, que são grupos independentes de vínculo presencial entre os membros. De acordo com a teoria, apesar de reconhecermos que o grupo LPTA e a disciplina homônima fazem parte do mesmo programa, não podemos dizer que os encontros em sala de aula sejam os encontros presenciais concernentes à comunidade de prática, pois a configuração do que acontece em sala de aula pouco tem a ver com o que acontece no grupo. 


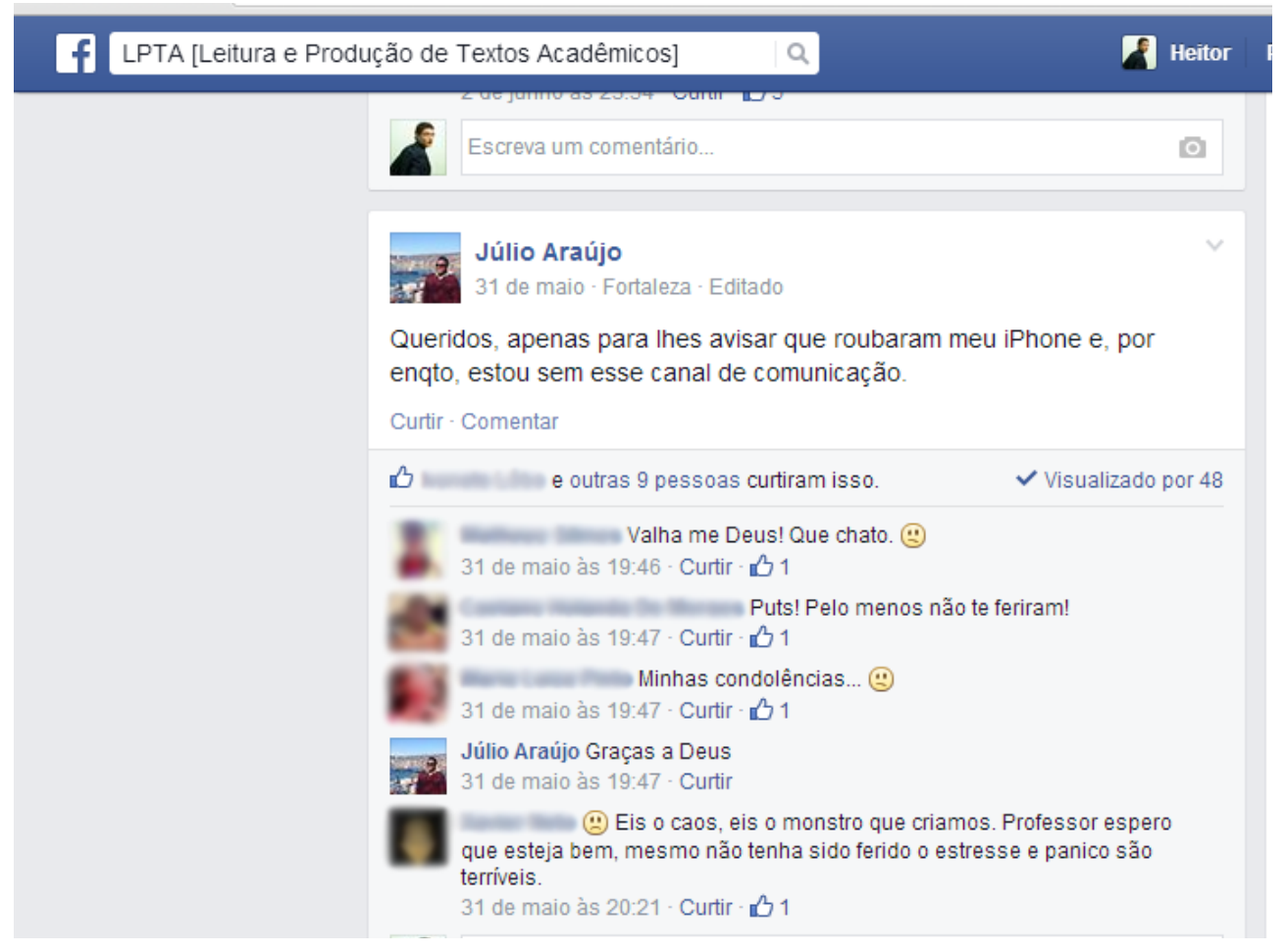

Figura 3- Recursos Tecnológicos

Isso nos justifica a relevância da informação para a qual o professor criou um tópico. Os alunos estavam adaptados a celeridade de trocas de turnos no grupo virtual e, pela mensagem postada pelo professor, ele usava muito seu dispositivo móvel para se comunicar mais rapidamente com a turma. Assim, ficar sem um telefone celular que suporte a plataforma de interação pela qual o grupo pode ser acessado, portanto, pode comprometer a interação no grupo de quem está sem esse dispositivo. A relevância, portanto, da postagem ilustrada pela fig.3é a de ressaltar que participação do professor no grupo seria um pouco menor, já que a mobilidade que tinha com seu dispositivo móvel havia sido, provisoriamente, suspendida.

Isso nos leva, finalmente, a ver como as tecnologias influenciam a existência e o andamento de uma comunidade de prática. A pesquisa de Cope; Kalantzis (2009), assim como a de Bevilaqua (2013, p. 103) relatam a preocupação dos estudiosos da área em "realizar discussões acerca dos efeitos do contexto contemporâneo altamente diversificado e crescentemente tecnologizado sobre a escola". Isso quer dizer que estudar gêneros no atual contexto de educação está se diferenciando cada vez mais do modelo típico de sala de aula presencial, dada a influência da tecnologia. Assim, comunidades (de prática) 
distribuídas que usam, por exemplo, redes sociais como uma plataforma que permite interação para além dos encontros presenciais em sala de aula, tendem a crescer muito mais enquanto grupo que se organiza em torno de objetivos comuns.

\section{Considerações finais}

De acordo com a análise feita nesse trabalho, podemos sugerir que o grupo LPTA no Facebook se configura como uma comunidade de prática, também chamada comunidade distribuída, uma vez que seu andamento não necessita de encontros presenciais, os quais não devem ser confundidos com encontros em sala de aula, tendo em vista as distintas configurações e funções.

Percebemos como a construção do conhecimento acontece de modo compartilhado e desnivelado, o que em nada tira o mérito do grupo. Aqueles que estão na área chamada "periferia", na qual observam e aprendem para depois participar, necessitam de alguém mais experiente para conduzir os tópicos que darão oportunidade para a participação de todos.

Observamos que os propiciamentos presentes na comunidade de prática estudada possibilitam para seus membros uma ampliação de seus letramentos acadêmicos, fortalecem a interação e, de certo modo, suprem suas necessidades. Além disso, os propiciamentos tendem a promover flexibilidade no modo de construção do grupo, na medida em que, por exemplo, todos têm à disposição recursos que permitem editar seus textos, o que favorece trocas mais ricas entre os membros.

\section{Referências}

ARAÚJO, J.; BARROS, M.G.; SILVA, E.S. Práticas de reescrita no ensino do gênero resenha. RBLA, Belo Horizonte, v. 15, n. 1, p. 109-130, 2015.

.; SILVA, P.H.; MARQUES, P.J. Complexidade e metáforas sistemáticas em cenas pedagógicas no Facebook. Trab. Ling. Aplic., Campinas, n(53.2): 425-448, jul./dez. 2014.

AZEVEDO, R.; NOVAIS, A. E. Leitura em Multimeios: as affordances no processo de interação em portais públicos: reses sociais e aprendizagem. In: Simpósio Hipertexto e Tecnologias na Educação, p.1.-20, 2010.

BEVILAQUA, R. Novos Estudos do Letramento e Multiletramentos: Divergências e Confluências. RevLet - Revista Virtual de Letras, Jataí , v. 5, n. 1, jan/jul, 2013. 
COPE, B.; KALANTZIS, M.A grammar of multimodality. International Journal of Learning, v. 16, n. 2, p. 361-425, 2009.

DIEB, M. O letramento acadêmico e a relação de estudantes do PET com a atividade de escrita na UFC. Relatório de Pós-Doutorado. São Cristóvão: Programa de Pós-Graduação em Educação. Universidade Federal de Sergipe, 2015.

LAVE, J.\& WENGER, E. Situated learning: Legitimate peripheral participation. New York: Cambridge University Press, 1991.

LEA, M. R.; STREET, B. V. The "Academic literacies" model: theory and applications, Theory Into Practice. Ohio, v. 45, n. 4, p. 368-377, out. 2006.

OLIVEIRA, D. V. De redes sociais a comunidades de prática: um estudo sobre percepção e efetivação de affordances no ambiente online. Domínios de Linguagem. Uberlândia, v. 6, n. 2, p. 170-190, 2012.

PAIVA, Vera L.M.O. Propiciamento (affordance) e autonomia na aprendizagem de língua inglesa In: LIMA, D. C. Aprendizagem de língua inglesa: histórias refletidas. Vitória da Conquista: Editora UESB, 2009.

RECUERO, R. Curtir, compartilhar, comentar: trabalho de face, conversação e redes sociais no Facebook. Verso e Reverso, São Leopoldo, v. 28, n. 68, maio-agosto 2014, pp. 114-124.

STREET, B. V. Letramentos sociais: abordagens críticas do letramento no desenvolvimento, na etnografia e na educação. Trad.: Marcos Bagno. São Paulo: Parábola Editorial, 2014.

SWALES, J.M. Communities of practice?. In: Other Floors, Other Voices: A Textography of a Small University Building. Mahwah: Lawrence Erlbaum Associates, 1998.

TUROLO-SILVA, A. Affordances e restrições na interação interpessoal escrita online durante a aprendizagem de inglês como língua estrangeira. Tese (Doutorado em Linguística). Fortaleza: Programa de Pós-Graduação em Linguística. Universidade Federal do Ceará, 2015.

VAN LIER, L. The Ecology and Semiotics of Language Learning. A Sociocultural Perspective. Boston: Kluwer Academic, 2004.

WENGER, E. C.; MCDERMOTT, R.; SNYDER, W. C. Cultivating Communities of Practice:A Guide to Managing Knowledge. Harvard Business School Press, Cambridge, USA, 2002.

RECEBIDO EM: 19/12/2015.

APROVADO EM: 23/02/2016. 